\title{
Design of a Library of Components for Autonomous Photovoltaic System under Matlab/Simulink
}

\author{
Ali Chermitti \\ URMER Research unit, \\ Tlemcen University, \\ B.P. 119, Tlemcen, Algeria
}

\author{
Omar Boukli-Hacene \\ Tlemcen University, \\ FT/GEE/Laboratory of \\ automatic B.P. 230, \\ Chetouane, Algeria
}

\author{
Samir Mouhadjer \\ URMER Research unit, \\ Tlemcen University, B.P. 119, \\ Tlemcen, Algeria
}

\begin{abstract}
This paper presents a library of components for PV systems under Matlab/Simulink, named " PV Systems Toolbox ". This toolbox allows analyzing the behavior of a PV system. It also estimates the power produced by the PV generator according to changes in climatic conditions and the nature of the load. An accurate model of the PV generator is presented based on the equation of the Shockley diode. A simple simulation example is given using a typical 60W PV module.
\end{abstract}

\section{General Terms}

Photovoltaic systems, Simulation, Library of components Photovoltaic power generator, Optimization system, Power, Regulation.

\section{Keywords}

Photovoltaic systems, Modeling, Simulation, Optimization, Library of components under Simulink.

\section{INTRODUCTION}

The prediction of the electrical behavior of a photovoltaic generator (GPV) is essential because it is the basis of the prediction of the energy that will be produced. This is a critical step in the design of any PV system. Simulation is a powerful tool for the theoretical performance evaluation of a system. In effect, it can be tested under conditions easily controlled and its performance can be readily monitored. The MathWorks MATLAB software and its associated graphical extension SIMULINK have the ability to simulate dynamic systems with ease and flexibility.

This paper is organized as follows: the PV generator is described in Part I. The impedance matching stage between a PV generator and a load is presented in Part II. The MPPT converter and some algorithms are described in Part III. The design of a library of components in Simulink is detailed in Part IV. Simulation results are shown in Section V, followed by a conclusion in section VI.

\section{THE PHOTOVOLTAIC GENERATOR}

Photovoltaic cells are semiconductor electronic components (usually made of silicon in its various forms). They convert directly light energy into low voltage DC electricity by the photovoltaic effect.

PV cell is the basic element of a PV system. A set of cells form a solar module in which the cells are electrically connected together and encapsulated, thus protected from external agents. Several modules form a solar panel. Several panels form a solar system or field, to which are added protections, a regulator, a system of energy storage (battery), control and measurement equipments and an inverter.

The term photovoltaic generator (PVG) is used to denote, according to the considered application, a module or a PV panel. However, it may refer to the entire PV system. For the remainder of this paper, we use the term PVG to refer to a module or a PV panel

\subsection{Modeling of the PV cell}

A PV cell can be represented by the equivalent electric circuit shown in figure 1 .

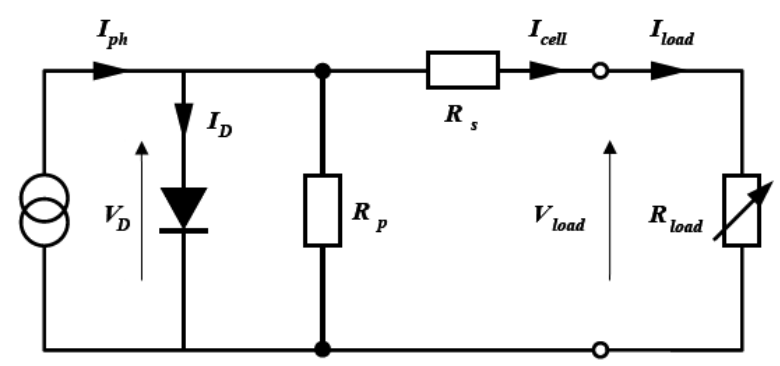

Fig 1: Equivalent electrical circuit of a PV cell connected to a load.

This circuit consists of a diode which represents the PN junction of the cell and a constant current source whose current amplitude depends on the intensity of the radiation. The parallel resistor $R_{P}$ characterizes the leakage current on the surface of the cell due to the non-ideality of the PN junction and impurities near the junction. The series resistor $R_{S}$ represents the various contact resistances and the resistance of the semiconductor. Currents and voltages are:

$I_{p h}$ : photocurrent, $I_{D}$ : current through the diode, $I_{\text {cell }}$ : current delivered by the cell, $V_{\text {cell }}$ : voltage across the cell, $I_{\text {load }}$ : current through the load, $V_{\text {load }}$ : voltage across the load.

With such an equivalent electrical circuit, one can obtain the following mathematical model of the PVcell : 
$I_{c e l l}=I_{p h}-I_{s}\left(e^{\frac{V_{c e l l}+R_{s} I_{c e l l}}{V_{t h}}}-1\right)-\frac{V_{c e l l}+R_{s} I_{c e l l}}{R_{p}}(1)$

where: $V_{t h}=n k T / q:$ is the thermal voltage

$q$ : elementary electric charge $\left[1.6 .10^{-19} \mathrm{As}\right]$

k: Boltzman constant $\left[1.381 .10^{-23} \mathrm{~J} / \mathrm{K}\right]$

$T$ : absolute temperature of the cell $\left[{ }^{\circ} \mathrm{K}\right]$

$I_{S}$ : saturation current of the unlighted junction $[A]$

$n$ : ideality factor of the junction.

For a more accurate modeling of the PV cell, the influence of the illumination level as well as the temperature must be taken into account. In practice, the cell parameters are given by the manufacturer under Standard Test Conditions (STC) or nominal as shown in Table 1.

Table 1. Nominal and standard test conditions

\begin{tabular}{|l|l|}
\hline \multicolumn{1}{|c|}{ Nominal Conditions } & \multicolumn{1}{c|}{ Standard Test Conditions } \\
\hline Irradiance: & Irradiance : \\
$G_{\text {nom }}=800 \mathrm{~W} / \mathrm{m}^{2}$ & $G_{O}=1000 \mathrm{~W} / \mathrm{m}^{2}$ \\
\hline Ambient temperature : & Cell temperature : \\
$T_{a, \text { nom }}=20^{\circ} \mathrm{C}$ & $T_{0}=25^{\circ} \mathrm{C}$ \\
\hline Wind Speed : $1 \mathrm{~m} / \mathrm{s}$ & $\mathrm{AM} 1.5$ (Air Mass) \\
\hline
\end{tabular}

Under standard test conditions (STC), the measured parameters are:

- the short-circuit current $I_{S C, 0}$

- the open circuit voltage $V_{O C, O}$

- the maximum power $P_{M A X, 0}$.

Under nominal conditions, the cell temperature $T_{N O C T}$ (NOCT : Nominal Operating Cell Temperature) is indicated on the manufacturer's catalog.

The photocurrent $I_{p h}$ is directly proportional to the illumination $G$ and also depends on température.

The serie resistance can be calculated using the expression(2):

$$
R_{s}=\left.R_{s}\right|_{T_{0}}\left(1+k_{1}\left(T-T_{0}\right)\right)
$$

with $k_{1}$ temperature coefficient of the serie resistance.

\subsection{Modeling of PVG}

The expression (1) gives an adequate representation of the intrinsic behavior of a typical silicon PV cell. Nevertheless, it can not be used directly to predict the behavior of PVG, because some parameters, $I_{p h}$ and $I_{s}$ in particular, can not be derived from informations generally available. These are restricted to the values of $I_{s c}^{*}, V_{o c}^{*}$ and $P_{\max }^{*}$ (STC) which are always included in the manufacturer's catalog.

To overcome this problem, some simplifications can be made by making the following assumptions [1] :

- the effect of parallel resistance is neglected,

- the photocurrent $I_{p h}$ and the short-circuit current $I_{s c}$ are equal,

- $\exp \left(\frac{V+I R_{s}}{V_{t h}}\right)>>1$ for all operating conditions.

We obtain the following model :

$$
I=I_{s c}\left[1-\exp \left(\frac{V-V_{o c}+I R_{s}}{V_{t h}}\right)\right]
$$

This expression is convenient because the right side parameters are easily determined, allowing its application directly. We obtain the PVG model given by expression (4) where the subscript " $P$ " indicates the parameters of the panel $[1],[5],[6],[12]$ :

$$
I^{P}=I_{s c}^{P}\left[1-\exp \left(\frac{V^{P}-V_{o c}^{P}+I^{P} R_{s}^{P}}{N_{s} V_{t h}^{C}}\right)\right]
$$

The expression of the panel current depends:

- on the panel short circuit current : $I_{s c}^{P}=N_{p} I_{s c}^{C}$

- $\quad$ on the open circuit voltage of the panel : $V_{o c}^{P}=N_{s} V_{o c}^{C}$

- on the serie resistance of PV panel : $R_{s}^{P}=\frac{N_{s}}{N_{p}} R_{s}^{C}$

Figure 2 illustrates the I/V characteristics of a PVG and a resistor. For a resistive load, the I/V characteristic is a straight line of slope $1 / R$. Therefore, if the resistance $R$ is small, the operating point is located in the region $\mathrm{AB}$ of the curve. The $\mathrm{PVG}$ behaves as a current generator. If the resistance $\mathrm{R}$ is large, the PVG operates in the region $\mathrm{CD}$. In this zone, the PVG behaves as a voltage source. In the region $\mathrm{BC}$ of the curve, the PVG can not be characterized neither by a current source nor by a voltage source. It is in this zone that we find the MPP (Maximum Power Point) for which the PVG provide its full power for certain atmospheric conditions. The resistance value corresponding to this point is denoted by $R_{\text {opt }}$ [5]. 


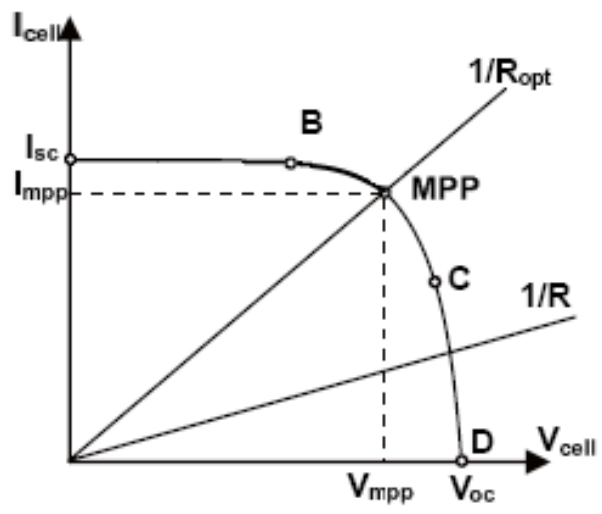

Fig 2: I/V Characteristic of a PVG and a load R

It is clear that the impedance of the load imposes the operating conditions of the PVG. In practice, in the case of a direct coupling of a PVG and a charge, the operating point rarely coincides with the MPP. For this reason, an impedence matching stage between the source and the load is required.

\section{Impedance matching stage between PVG and a load}

To extract, at each moment, the maximum power available at the terminals the PVG and transfer it to the load, an impedance matching stage is used. This stage acts as an interface between the two elements. It ensures, through a control action, the transfer of maximum power delivered by the generator. The commonly used adapter in PV is a Static Converter (DC/DC power converter). The conversion structure is selected according to the load to be supplied. It can be step-up or step-down.

\subsection{Step-down converter (Buck converter)}

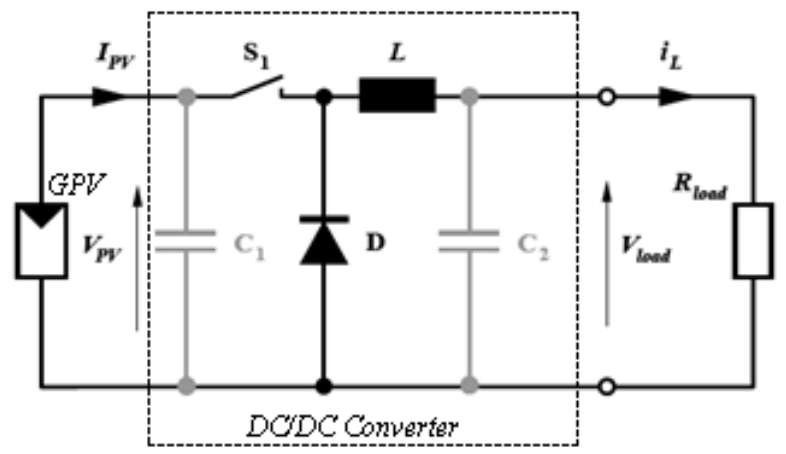

Fig 3: DC/DC converter between the PVG and a load

Figure 3 shows the representation of a DC / DC converter, which can be used as an interface between PVG and the load $[1,8,9,10,11]$. It's a buck converter.

The role of DC/DC converter in the PV system is to make the adjustment between the PVG and the charge for an optimal power transfer. This is done by keeping the operating point (OP) on or fairly close to the MPP for any operating conditions (radiance, temperature, load characteristics, etc..). The DC/DC converter is used to regulate the input voltage
$V_{p v}$. The reference voltage is then constant or imposed by a control algorithm. In the following, the principle of operation of $\mathrm{DC} / \mathrm{DC}$ step down converter is described.

Buck converter is a switching power supply that converts a DC voltage into another DC voltage of lower value. This type of converter is used as an adapter between source and load when the operating point in direct coupling is to the left of the MPP.

In this case, the voltage across the load in continuous conduction mode is given by :

$V_{\text {load }}=D \cdot V_{P V}$

where $D=\frac{t_{o n}}{T}:$ is the duty cycle $(0<D<1)$

$T=t_{\text {on }}+t_{\text {off }}$ : is the switching period

Generally, the DC/DC converters switch is controlled by a PWM signal (Pulse Width Modulation). A PWM signal is a rectangular signal of fixed frequency, but whose duty ratio $D$ is variable. The value of the duty cycle allows to control the amount of energy transmitted.

\section{The MPPT converter}

The power delivered by a PVG strongly depends on the sunlight level, temperature and also the nature of the supplied load. It is therefore very unpredictable. As shown in figure 4, the power characteristic of PVG has a maximum power point MPP corresponding to a certain operating point of coordinates $V_{M P P}$ for voltage and $I_{M P P}$ for current. Since the position of the MPP depends on the level radiation and cell temperature, it is never constant over time. A MPPT Converter (Maximum Power Point Tracker) must be used to track the MPP. A MPPT converter is a power conversion system with an appropriate control algorithm for extracting the maximum power that can provide the PVG.

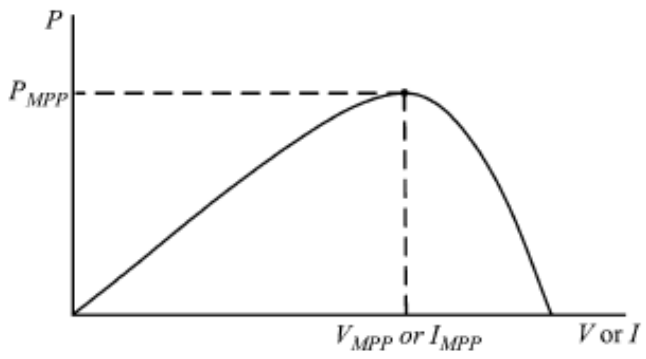

Fig 4: Power characteristic curve of a PVG

\subsection{Principle of the MPP research}

Figure 5 shows the block diagram of a typical MPPT converter. The MPPT control varies the duty cycle of the DC/DC converter using a PWM signal. The MPPT algorithm is based on the variation of the duty cycle of the DC/DC converter in response to changing input parameters (I and V and therefore the power of PVG) to be placed on the MPP. 


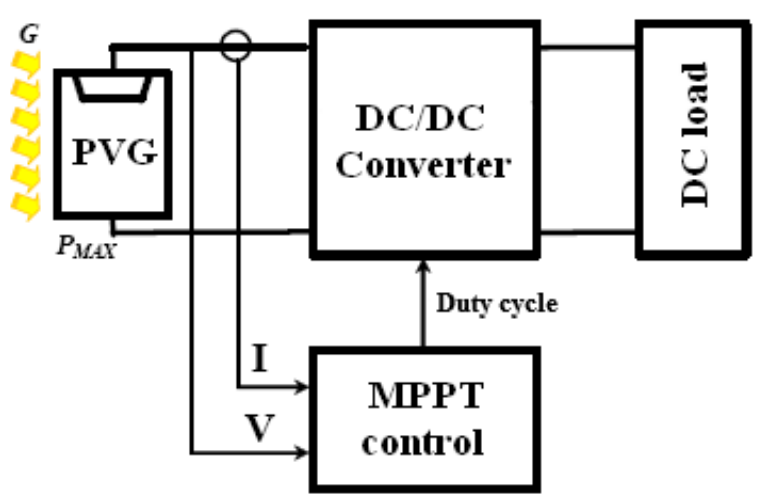

Fig 5: Schematic diagram of the MPPT converter

Several algorithms are presented in the literature. The most used are $[2,4,14,15,16]$ :

- Perturb and Observe algorithm (P\&O)

- Incremental Conductance algorithm (IncCond)

\subsection{Perturb and Observe algorithm (P\&O)}

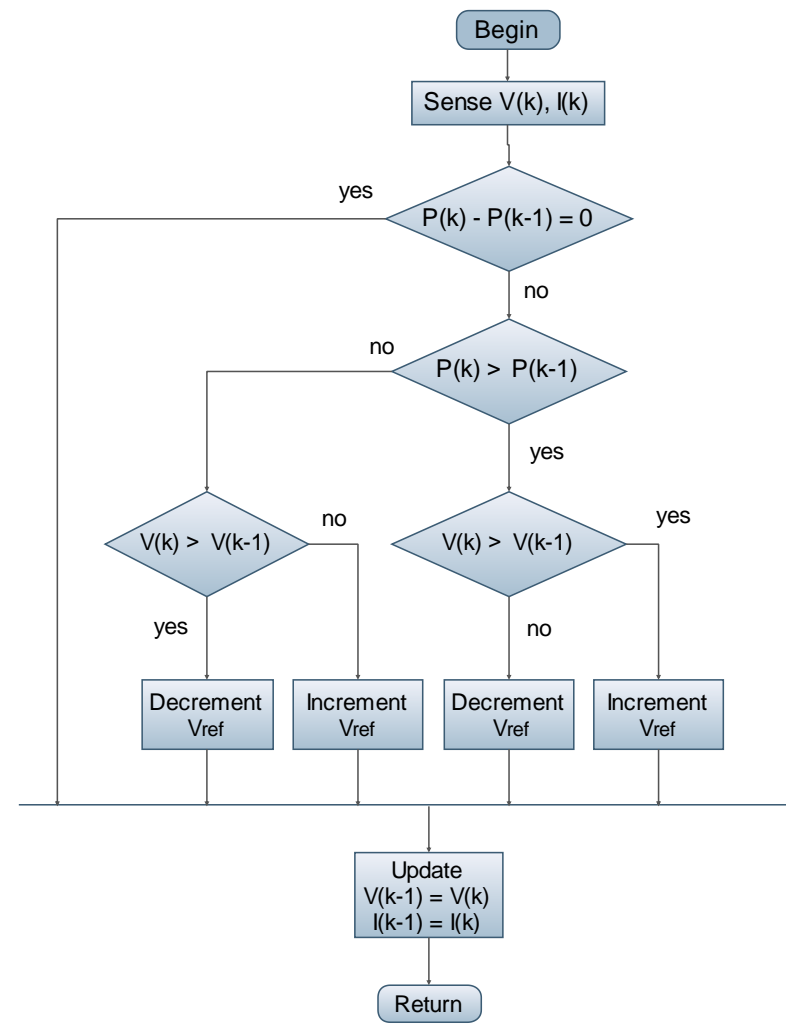

Fig 6: Chart of the P\&O algorithm

The P\&O method is generally the most used because of its simplicity and ease of implementation. As its name implies, this method works by disrupting the system and observing the impact on power output of PVG. On figure 4, we can see that if the operating voltage is disturbed in a given direction and that the power increases $(\mathrm{dP} / \mathrm{dV}>0)$ then it is clear that the disturbance has moved the operating point toward the MPP. The $\mathrm{P} \& \mathrm{O}$ algorithm will continue to disturb the voltage in the same direction. By cons, if the power drops $(\mathrm{dP} / \mathrm{dV}<0)$, then the disturbance has moved the operating point far from the MPP. The algorithm will reverse the direction of subsequent disturbance. This algorithm is summarized in the flowchart in figure $6[2,12]$.

\subsection{Incremental Conductance algorithm (IncCond)}

This method is based on the fact that the slope of the power curve of the panel is zero at the MPP, positive to the left and negative to right $[2,4,16]$. This method is based on the fact that the slope of the power curve of the panel is zero at the MPP, positive to the left and negative to right $[2,4,16]$.

Since $\frac{d P}{d V}=\frac{d(I V)}{d V}=I+V \frac{d I}{d V} \cong I+V \frac{\Delta I}{\Delta V}$,

$\begin{cases}\frac{\Delta I}{\Delta V}=-\frac{I}{V} & \text { at the MPP } \\ \frac{\Delta I}{\Delta V}>-\frac{I}{V} & \text { left of the MPP } \\ \frac{\Delta I}{\Delta V}<-\frac{I}{V} & \text { right of the MPP }\end{cases}$

The MPP can be tracked by comparing the instantaneous conductance ( $G_{c i}=I / V$ ) to the incremental conductance ( $\Delta G_{c i}=\Delta I / \Delta V$ ), as shown in the flowchart of figure 7 .

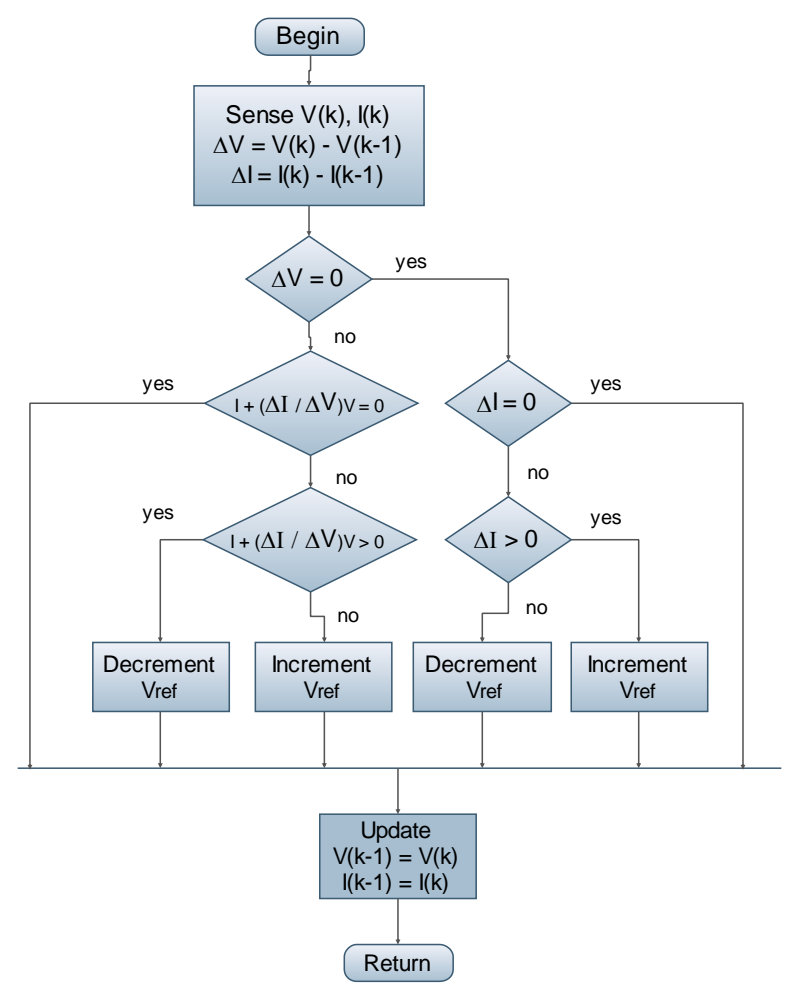

Fig 7: Chart of the IncCond algorithm 
$V_{r e f}$ is the reference voltage for which the PV panel is forced to operate at the MPP, $V_{r e f}=V_{M P P}$. Once the MPP is reached, the operating point correspendant is maintained, unless a change in $\Delta I$ is observed, indicating a change in atmospheric conditions and therefore the MPP. The algorithm increases or decreases $V_{r e f}$ to track the new MPP.

The size of the increment determines the speed of the tracking of MPP. A fast tracking can be obtained with a larger increment, but the system could not operate exactly at the MPP and oscillates around it. So there are, as for the P\&O algorithm, a compromise between speed and accuracy. This method can be improved by moving the operating point near the MPP in a first step, then use the IncCond algorithm to track exactly the MPP in a second step.

\section{Design of a Simulink Components Library}

The MATLAB software of MathWorks' and its associated graphical extension Simulink have the ability to simulate mixed dynamical systems (continuous and discrete). It is therefore well suited to implement, test, simulate and evaluate the PV systems. For this we have designed a variety of components that form a library for the simulation of PV systems in Simulink.

\subsection{PVG model}

We have used the mathematical model of the PVG given by expression (4) to design a component in Simulink representing the PVG. Figure 8 shows the component PVG where $\mathrm{G}$ is the level of radiation $\left(W / m^{2}\right), T_{a}$ is ambient temperature $\left({ }^{\circ} C\right), V_{p}$ is the PVG voltage $(\mathrm{V})$ and $I_{p}$ is the current PVG (A). The Simulink model of figure 8 has as output the current of the PVG. It is well adapted for a parallel connection of several PV modules that share the same voltage. However, this model can be used to build another model (figure 8) which has as output the voltage of the PVG. The latter is well adapted for a series connection of several PV modules that share the same current. The Simulink block diagram of this model is shown in figure 9.

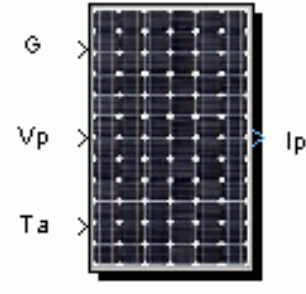

PVG (current output)

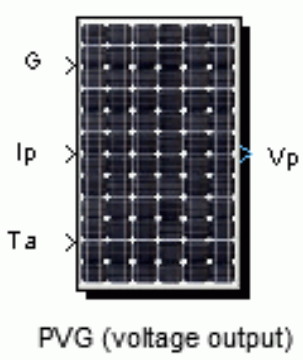

PVG (voltage output)
Fig 8 : Simulink blok representing the PVG.

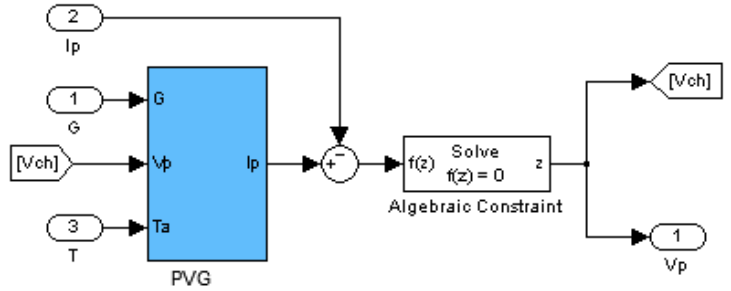

Fig 9: Block diagram of the PVG having voltage as output.

\subsection{Statique Converter model (SC)}

To simulate the behavior of the SC, we have used the SimPowerSystems package integrated to Simulink, which is a set of electrical components for power electronics. The simulation model of Buck converter is shown in figure 10 as an example. The components used in this model are ideal. This model is used to create a component representing the Buck converter. The other types of DC/DC converter can be easily designed using the package SimPowerSystems.

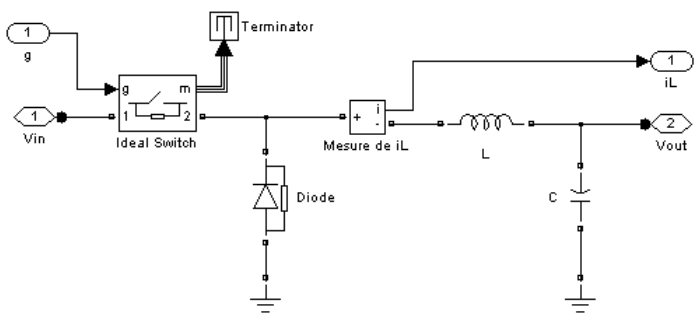

Fig 10: Simulation model of Buck converter using the package SimPowerSystems.

\subsection{MPPT algorithms models}

We have designed a simulation model of the $\mathrm{P} \& \mathrm{O}$ algorithm (figure 11), based on the flow chart shown in figure 6.

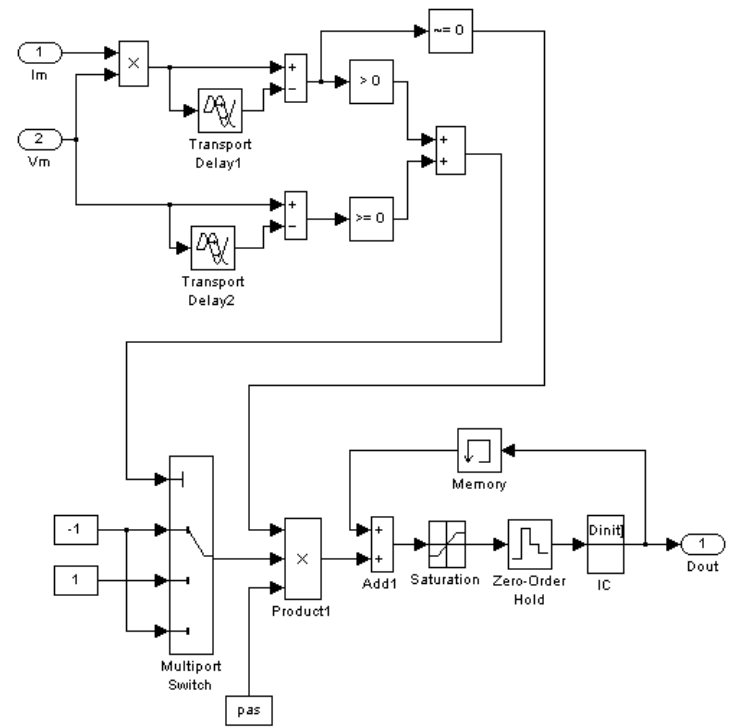

Fig 11. SIMULINK model of the P\&O MPPT algorithm 
Similarly, the flowchart in figure 7, allowed us to design the model of the IncCond algorithm shown in figure 12.

\section{Simulation Results}

To perform the simulation, we selected the MSX60 Solarex module that provides a nominal power of $60 \mathrm{~W}$. It consists of 36 polycrystalline silicon cells and its main characteristics are given in Table 2. The values of the different components of the Buck converter used in the simulation are : inductance of $120 \mu \mathrm{H}$, an input capacitor of $100 \mu \mathrm{F}$ and an output capacitor of $100 \mu \mathrm{F}$. The connected load is a simple resistor. The switching frequency of the Buck converter is $100 \mathrm{kHz}$ and the chosen MPPT frequency is $500 \mathrm{~Hz}$. The initial duty cycle is $30 \%$.

Table 2. Characteristics of the MSX60 Solarex pannel

Parameter Variable Value

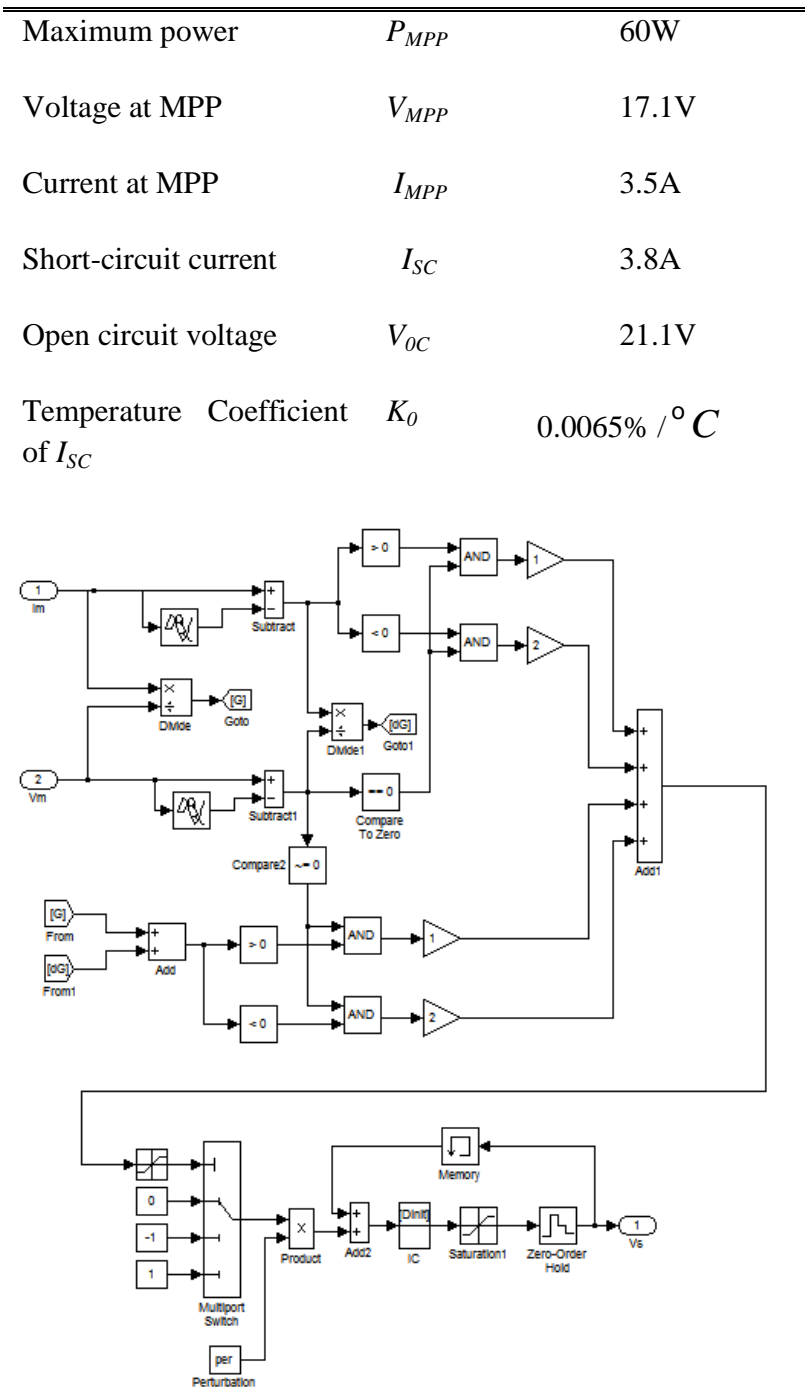

Fig 12: SIMULINK model of the IncCond MPPT algorithm
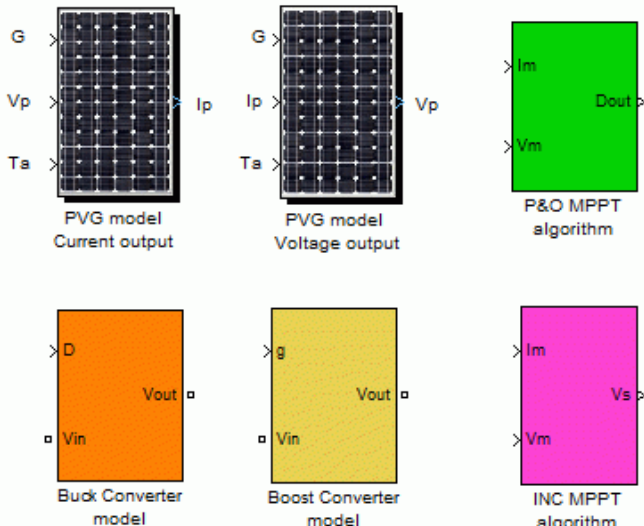

Fig 13: Component library for a PV system "Photovoltaic Systems Toolbox".

\subsection{Operating under stable climatic conditions}

In this section, the atmospheric conditions correspond to the STC (radiation of $1000 \mathrm{~W} / \mathrm{m}^{2}$ and an ambient temperature of $25^{\circ} \mathrm{C}$ ). The simulation results are shown in figures 14 and 15 for a duty cycle perturbation of $10 \%$ and in figures 16 and 17 for a perturbation of $2 \%$.
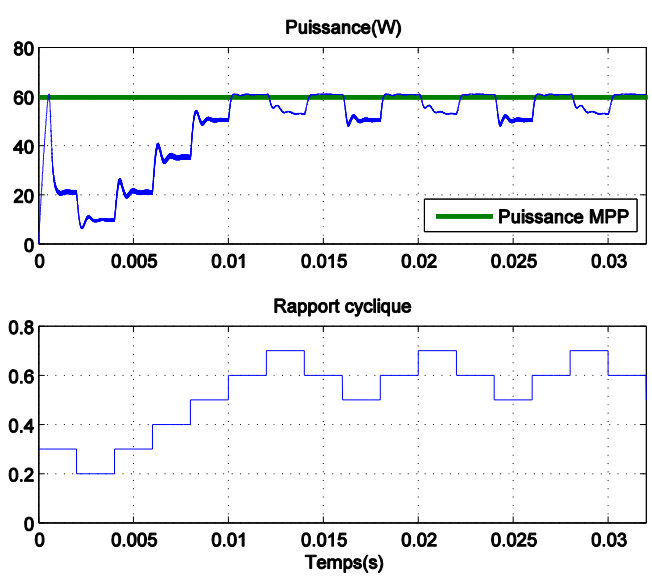

Fig 14: Power (top), and duty cycle for a perturbation of $10 \%$
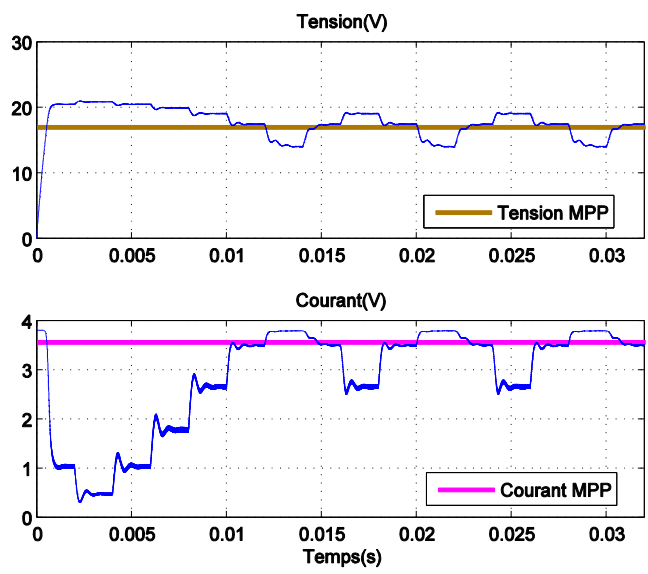

Fig 15: Voltage and current of PVG for a perturbation of $10 \%$ 

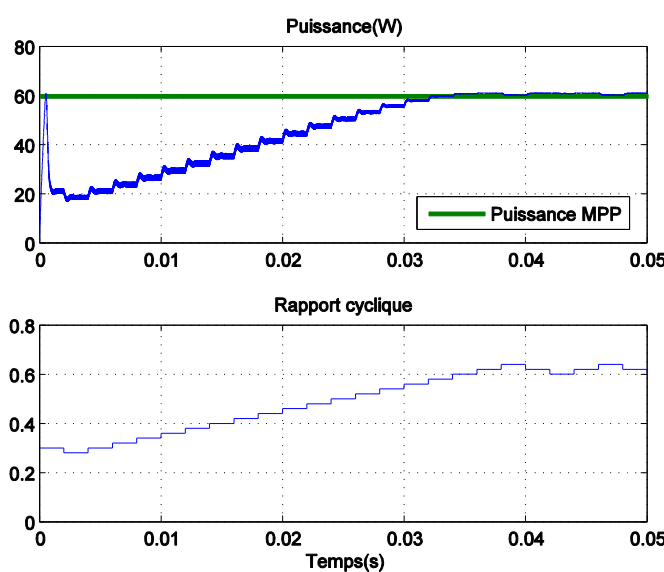

Fig 16 : Power and duty cycle for a perturbation of $2 \%$

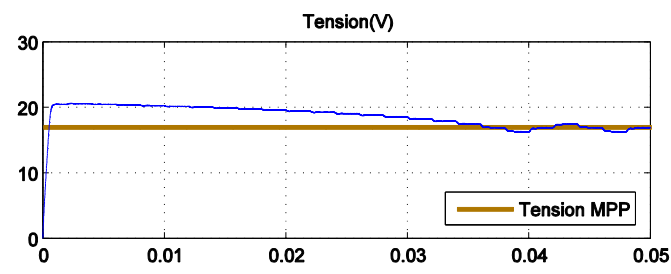

Courant( $(\mathrm{V})$

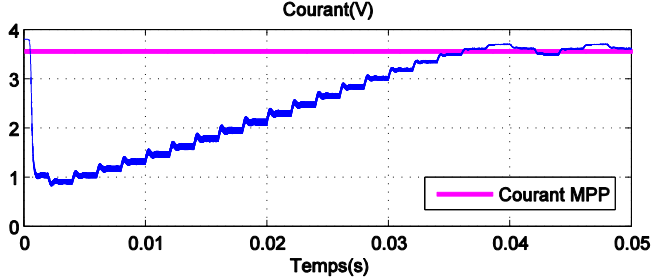

Fig.20: Voltage and current of PVG for a perturbation of $2 \%$.

\section{Conclusion}

In this paper, we presented the design of a component library for a PV system under Simulink. The library, named "Photovoltaic Systems Toolbox" consists of a precise model representing the PVG, model designating the SC and finally two models to simulate algorithms MPPT P\&O and IncCond. The library, named "Photovoltaic Systems Toolbox" consists of a precise model representing the PVG, a model denoting the SC and finally two models to simulate $\mathrm{P} \& \mathrm{O}$ and IncCond MPPT algorithms. The simulation results using a typical $60 \mathrm{~W}$ PV module have shown a good representation of the behavior of a PV system.

\section{REFERENCES}

[1] Antonio Luque and Steven Hegedus 2003. Handbook of Photovoltaic Science and Engineering, John Wiley \& Sons Ltd,
[2] Akihiro Oi, 2005. Design and Simulation of Photovoltaic Water Pumping System, Faculty of California Polytechnic State University,

[3] DenHerder T. 2006. Design and Simulation of Photovoltaic Super System Using Simulink", California Polytechnic State University.

[4] Sannella N. P. 2005. analysis and Simulation Tools for Solar Array Power Systems, University of Central Florida,

[5] Lionel Vechiu, 2005. Modélisation et Analyse de l'Intégration des Énergies Renouvelables dans un Réseau Autonome", Université du Havre.

[6] A.D. Halmsen et al, 2000. Models for a Stand-Alone PV System", University of Denmark.

[7] Dezso S. Remus T. 2006. PV panel model based on datasheet values", Aalborg University.

[8] Zenati A. 2007. Modélisation et simulation de microsystèmes multi domaines à signaux mixtes : vers le prototypage virtuel d'un microsystème autonome, Université Joseph Fourier Grenoble I,

[9] Erickson R.W. 1997. Fundamentals of Power Electronics, Chapman \& Hall, 115 Fifth Avenue, New York, NY 10003,.

[10] Bausière R. Labrique F. Seguier G. 1997. Les Convertisseurs de l'Electronique de Puissance Volume 3 : La Conversion Continue - Continue (2ème édition)", Paris : Lavoisier-Tec \& doc

[11] Mohan N. Undeland T.M. Robbins W.P. 2003. Power Electronics Converters, Applications And Design", John Wiley \& Sons, INC,

[12] Xiao W. 2003. A Modified Adaptative Hill Climbing Maximum Power Point Tracking (MPPT) Control Method For Photovoltaic Power Systems, The University of British Columbia,

[13] Angel M. Cid Pastor 2006. Conception et Réalisation de Modules Photovoltaques Electroniques, Institut National des Sciences Appliquées de Toulouse.

[14] Persen T.E. 2004. FPGA-Based Design of a MaximumPower-Point-Tracking System for Space Applications", University of Florida,

[15] Salas V. , Olias E., Barrado A. , A. Lazaro, (2006) Review of the maximum power point tracking algorithms for stand-alone photovoltaic systems, Solar Energy Materials \& Solar Cells 90 1555-1578

[16] Esram T. , Patrick L., Y.T. Yu, M.F. Lau, 2006, Comparison of Photovoltaic Array Maximum Power Point Tracking Techniques, IEEE TRANSACTIONS ON ENERGY CONVERSION. 